\title{
Correction to: Bumetanide Oral Liquid Formulation for the Treatment of Children and Adolescents with Autism Spectrum Disorder: Design of Two Phase III Studies (SIGN Trials)
}

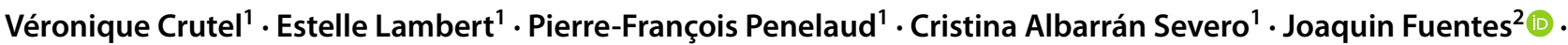 \\ Antoine Rosier ${ }^{3} \cdot$ Amaia Hervás $^{4} \cdot$ Stéphane Marret $^{5,6} \cdot$ Guiomar Oliveira $^{7,8} \cdot$ Mara Parellada $^{9} \cdot$ Simon Kyaga $^{10}$. \\ Sylvie Gouttefangeas ${ }^{1} \cdot$ Marianne Bertrand $^{1} \cdot$ Denis Ravel $^{11} \cdot$ Bruno Falissard $^{12}$
}

(c) The Author(s) 2020

\section{Correction to: Journal of Autism and Developmental Disorders https://doi.org/10.1007/s10803-020-04709-8}

The author of the article would like to add a video abstract as a supplementary material for a published article. The supplementary file is published with this correction.

The original article has been corrected.
Supplementary Information The online version of this article (https:// doi.org/10.1007/s10803-020-04822-8) contains supplementary material, which is available to authorized users.

Open Access This article is licensed under a Creative Commons Attribution 4.0 International License, which permits use, sharing, adaptation, distribution and reproduction in any medium or format, as long as you give appropriate credit to the original author(s) and the source, provide a link to the Creative Commons licence, and indicate if changes were made. The images or other third party material in this article are included in the article's Creative Commons licence, unless indicated
The original online version of this article was revised: Video Abstract has been added as an Electronic Supplementary material.

The original article can be found online at https://doi.org/10.1007/ s10803-020-04709-8.

Simon Kyaga

simon.kyaga@servier.com

1 Neuro Immuno-Inflammation Therapeutic Area, Institut de Recherches Internationales Servier, Suresnes, France

2 Child \& Adolescent Psychiatry Service, Policlínica Gipuzkoa \& GAUTENA Autism Society, San Sebastián, Spain

3 Department of Neonatal Pediatrics, CHU de Rouen and CHU Le Rouvray, Sotteville les Rouen, France

4 Child and Adolescent Mental Health Service, Hospital Universitari Mútua de Terrassa, and Global Institute of Neurodevelopment Integrated Care (IGAIN), Barcelona, Spain

5 Department of Neonatal Pediatrics, Intensive Care, and Neuropediatrics, Rouen University Hospital, Rouen, France

6 INSERM U 1245 team 4 Neovasc, School of Medicine, Normandy University, Rouen, France
7 Neurodevelopmental and Autism Unit from Child Developmental Center and Centro de Investigação e Formação Clínica, Hospital Pediátrico, Centro Hospitalar e Universitário de Coimbra, Coimbra, Portugal

8 Faculty of Medicine, University Clinic of Pediatrics, University of Coimbra, Coimbra, Portugal

9 Servicio de Psiquiatría del Niño y del Adolescente Hospital General Universitario Gregorio Marañón, CIBERSAM, IiSGM, Ibiza 43, Madrid, Spain

10 Global Medical and Patient Affairs, Servier, 35 rue de Verdun, 92284 Suresnes cedex, Suresnes, France

11 Neurochlore, Marseille, France

12 University Paris-Sud, Univ. Paris-Descartes, AP-HP, INSERM U1178, Paris, France 
otherwise in a credit line to the material. If material is not included in the article's Creative Commons licence and your intended use is not permitted by statutory regulation or exceeds the permitted use, you will need to obtain permission directly from the copyright holder. To view a copy of this licence, visit http://creativecommons.org/licenses/by/4.0/.
Publisher's Note Springer Nature remains neutral with regard to jurisdictional claims in published maps and institutional affiliations. 